\title{
A FORMAÇÃO DOCENTE NA EDUCAÇÃO INFANTIL: LEVANTAMENTO DE NUANCES
}

\author{
Jany Rodrigues Prado ${ }^{1}$, Regivane dos Santos Brito ${ }^{2}$, Claudio Pinto Nunes ${ }^{3}$ \\ ${ }^{1}$ Mestre em Educação pela Universidade Estadual do Sudoeste da Bahia - UESB. Docente substituta da Universidade \\ Estadual da Bahia - UNEB, Departamento de Educação de Guanambi - Campus XII. E-mail: janyrprado@yahoo.com.br \\ ${ }^{2}$ Mestre em Educação pela Universidade Estadual do Sudoeste da Bahia - UESB. Membro do Grupo de Pesquisas sobre \\ Didática, Formação e Trabalho Docente (Difort/CNPq). E-mail: regivanne brito@live.com \\ ${ }^{3}$ Doutor em Educação pela Universidade Federal do Rio Grande do Norte - UFRN. Docente do Programa de Pós- \\ Graduação em Educação da Universidade Estadual do Sudoeste da Bahia - UESB. E-mail: \\ claudionunesba@hotmail.com
}

\section{RESUMO}

Este artigo apresenta um breve retrospecto do cenário histórico e político da educação infantil e a legislação pertinente a essa etapa da educação básica, a fim de analisar os sentidos que os professores da educação infantil da rede municipal de Guanambi - BA atribuem a sua formação. A abordagem metodológica encontra-se ancorada na pesquisa qualitativa (BOGDAN; BIKLEN, 1994) que procura buscar modelos compreensivos do fenômeno estudado. Como instrumento de produção de informações, utilizouse as conversas interativo-provocativas (NUNES, 2011). As questões abordadas ratificam a desvalorização e o dualismo que envolvem os profissionais que trabalham com este segmento. Refletem ainda a estruturação histórica que compreendeu e ainda compreende a educação infantil como etapa da educação básica voltada apenas ao cuidar e ao âmbito das políticas educacionais centradas no assistencialismo, no voluntariado, o que tem certamente contribuído para as precárias condições de trabalho docente e para precarização do profissionalismo. A análise revelou que, nos últimos anos, foram criadas importantes políticas rumo à educação de qualidade para as crianças pequenas. Entretanto, existem ainda muitos enfrentamentos que envolvem a educação infantil. Dentre eles, o da formação docente que se configura como um dos maiores, principalmente ao se pensar as condições de trabalho docente, pois pressupõe a revisão do status desse profissional, seu plano de carreira, sua remuneração, enfim sua profissionalização. Tais desafios se colocam ainda como impasses no atual momento histórico e político, marcado por um cenário turbulento, instável e ameaçador que se materializa em ações que afetam diretamente setores sociais como a educação.

Palavras-chave: Educação Infantil; Formação Docente; Políticas Educacionais.

\section{THE TEACHER TAINING IN THE CHILDREN EDUCATION: LIFTING OF NUANCES}

\section{ABSTRACT}

This article show a brief retrospective of the historical and political scenario of the child education and the relevant legislation to this stage of the basic education, to analyze the meanings that the preschool teachers of the municipal network of Guanambi - BA attribute to their formation. The methodological approach is assured on the qualitative research (BOGDAN; BIKLEN, 1994) looking comprehensive examples of the studied phenomenon. As production tool of information, provocative interactive conversations were used (NUNES, 2011). The alluded questions ratify the devaluation and the dualism that involv working professionals with this segment. Still reflect the historic structuration that understood and still understand the child education as stage basic education geared only to the careful under educational politic centered on the welfare, on the volunteering, that has certainly contributed to the conditions precarious of teaching work e to precariousness professionalism. The analyze showed that, in the last years were created political important toward to the quality education to the small children. Meantime, there are many clashes involving the child education. Among them, of the teacher training introduce himself as one of the biggest when thinking in conditions of the teaching work, because it presupposes the revision of status this 
professional, your career plan, your remuneration, finally your professionalization. This challenges put themselves hindrances in the current politic moment, marked by turbulent scenario, unstable and threatening that materializes in actions that directly affect social sectors as education.

Keywords: Child Education; Professional Qualification; Educational Policies.

\section{EDUCACIÓN DOCENTE EN EDUCACIÓN INFANTIL: LEVANTAMIENTO DE NUANCES}

\section{RESUMEN}

Este artículo presenta una breve retrospectiva del escenario histórico y político de la educación de la primera infancia y la legislación pertinente en esta etapa de la educación básica, a fin de analizar los significados que los maestros de jardín de infantes de la red municipal de Guanambi - BA atribuyen a su formación. El enfoque metodológico está anclado en la investigación cualitativa (BOGDAN; BIKLEN, 1994) que busca modelos integrales del fenómeno estudiado. Como instrumento de producción de información, se utilizaron conversaciones interactivas provocativas (NUNES, 2011). Los temas abordados ratifican la devaluación y el dualismo que rodea a los profesionales que trabajan en este segmento. También reflejan la estructura histórica que entendió y aún comprende la educación de la primera infancia como una etapa de la educación básica centrada solo en el cuidado y el alcance de las políticas educativas centradas en el bienestar, el voluntariado, que ciertamente ha contribuido a las precarias condiciones de trabajo y la precariedad de la profesionalidad. El análisis reveló que en los últimos años se han implementado políticas importantes para una educación de calidad para los niños pequeños. Sin embargo, todavía hay muchas confrontaciones relacionadas con la educación de la primera infancia. Entre ellos, la formación docente es una de las más importantes cuando se piensa en las condiciones laborales de los docentes, ya que presupone la revisión del estado de este profesional, su plan de carrera, su compensación y, finalmente, su profesionalización. Tales desafíos son aún como impases en el momento histórico y político actual, marcado por un escenario turbulento, inestable y amenazante que se materializa en acciones que afectan directamente a sectores sociales como la educación.

Palabras clave: Educación de la Primera Infância; Formación del Professorado; Políticas Educativas.

\section{INTRODUÇÃO}

Este texto é um recorte da pesquisa de mestrado intitulada os sentidos que os professores da educação infantil do município de Guanambi - BA atribuem a sua condição de trabalho docente, desenvolvida no ano de 2017, na qual foram apresentados os sentidos atribuídos pelos professores aos modos de estar na educação infantil, enfatizando os processos de formação continuada, vivenciados no exercício da profissão docente na educação infantil na rede municipal de Guanambi.

Constitui-se em uma pesquisa de relevância científica, pois apresenta informações que podem ampliar os conhecimentos existentes sobre o tema, ajudando a construir um arcabouço teórico sobre a formação docente na educação infantil e pode suscitar também novas investigações na área. Além disso, é uma pesquisa de relevância social, já que contribui com a divulgação sobre o processo histórico e político da educação infantil, de modo que os interessados no tema possam compreender como esses processos reverberam no perfil e na formação dos profissionais que atuam na primeira etapa da educação básica.

Desse modo, este artigo apresenta um breve retrospecto do cenário histórico e político da educação infantil e a legislação pertinente a essa etapa da educação básica, a fim de analisar os sentidos que os professores da educação infantil da rede municipal de Guanambi - BA atribuem a sua formação.

\section{DELINEAMENTO METODOLÓGICO}

O objeto de estudo desta investigação é a formação docente na educação infantil e encontra-se ancorado na pesquisa qualitativa, por conta das características do objeto a ser pesquisado e do objetivo que a norteia. Dessa forma, como sugerem Alves-Mazzotti e Gewandszajder (2004) a investigação naturalística, o recurso descritivo, a interpretação em contexto, a maior ênfase no processo do que no produto, a valorização da apreensão dos significados atribuídos pelos pesquisadores aos fenômenos estudados foram aspectos estruturantes desta pesquisa. 
A presente investigação foi desenvolvida em Guanambi, município do interior da Bahia, distante a 796 quilômetros da capital do estado, localizado no território 13 - Sertão Produtivo. E contou com a participação de seis professores da educação infantil da rede municipal de ensino, que voluntariamente se dispuseram a ser os sujeitos desta investigação por meio da adesão. Após serem informados sobre os objetivos e os procedimentos da pesquisa, cada um deles assinou o Termo de Consentimento Livre e Esclarecido, confirmando sua participação. No intuito de preservar a identidade dos participantes, seus nomes foram substituídos por nomes fictícios.

Como instrumento de produção de informações, utilizou-se as conversas interativoprovocativas (CIPs) (NUNES, 2011). Tal instrumento encontra-se também ancorado na pesquisa qualitativa que destaca as conversações como modo de expressão do sujeito, como melhor exemplo de comunicação interativa. Nunes (2011) destaca a importância da atitude provocativa do pesquisador, que de posse de um roteiro semiestruturado, orienta os rumos da conversa, a fim de responder às questões propostas pela pesquisa, tendo sempre o cuidado de não interromper o raciocínio dos sujeitos. Assim, o pesquisador assume o compromisso de possibilitar a expressão livre e espontânea dos sujeitos, considerando que eles estão cientes do objeto de estudo, os objetivos da pesquisa e a relevância científica, acadêmica e social de sua participação. Nesse processo de conversação, pesquisados e pesquisador se envolvem num clima de produção de informações.

Ressalta-se que esta pesquisa foi aprovada pelo Comitê de Ética em Pesquisa (CEP), da Universidade Estadual do Sudoeste da Bahia - UESB e atende às recomendações da Comissão de Ética em Pesquisa (CONEP).

\section{O cenário histórico e político da educação infantil: algumas aproximações}

A atual configuração da educação infantil como direito da criança e como espaço coletivo de educação de crianças de 0 a 5 anos teve início recentemente no Brasil. Até meados do século $X I X$, não se tem registros no Brasil do atendimento a crianças pequenas longe das mães em instituições, como creches ou jardins de infância.

Esse cenário começou a se alterar, a partir da segunda metade do século XIX, quando alguns fatos históricos colaboraram para o delineamento de novas demandas no atendimento de crianças dessa faixa etária, como: aumento da migração de moradores da zona rural para zona urbana das grandes cidades; Proclamação da República e o desejo de uma elite política em construir uma nação moderna alicerçada em preceitos europeus, como a ideia de jardim de infância; o discurso de culpabilização das famílias mais pobres por eventuais doenças de seus filhos e a compreensão da creche como instituição capaz de oportunizar o desenvolvimento saudável das crianças.

Nesse percurso, outros marcos históricos são importantes para a criação de políticas públicas para as crianças da educação infantil, conforme assevera Pinto (2009, p. 29):

Os marcos importantes na trajetória de construção da política de educação das crianças de zero a seis anos, no país, referem-se à pressão advinda dos movimentos sociais, principalmente feministas, em defesa da expansão do atendimento; às mudanças no perfil sociodemográfico da sociedade brasileira (diminuição no tamanho das famílias, participação crescente das mulheres no mercado de trabalho e urbanização da população); e aos estudos científicos sobre o desenvolvimento infantil. Todos esses aspectos trouxeram avanços legais e a necessidade de políticas públicas que reconhecessem as crianças como cidadãs, instaurando também novas exigências de qualificação para as profissionais que atuam nessa etapa da educação básica.

Rosemberg (2003), ao traçar o panorama da educação infantil brasileira contemporânea, destaca três períodos históricos também como marcos na construção de políticas públicas para esse segmento da educação básica. O primeiro, entre o final da década de 1970 e o início da 
década de 1980, refere-se a um modelo denominado pela autora como modelo de massa, modelo de baixo custo que procurava atender o maior número possível de crianças sem priorizar um atendimento de qualidade, mas voltado para suprir carências culturais, deficiências linguísticas e defasagens afetivas das crianças provenientes das camadas populares. Tal modelo encontra-se alicerçado nas diretrizes do Fundo das Nações Unidas para a Infância (UNICEF) e da Organização das Nações Unidas para Educação, Ciência e Cultura (UNESCO) e destaca-se pela política compensatória e discriminatória. E se apoia no discurso das habilidades naturais da mulher para cuidar das crianças pequenas, reiterando a ideia de que para ser "educadora" basta ser mulher, gostar de crianças e apresentar habilidades maternas.

O segundo período tem início após a ditadura militar e é marcado pela forte ação dos movimentos sociais. Nesse período, há um avanço na construção de uma concepção da educação infantil, pois compreende esta etapa da educação como direito da criança pequena, bem como o direito de homens e mulheres trabalhadoras terem seus filhos cuidados e educados em instituições como creches e préescolas. Ocorre, assim, o reconhecimento legal com a Constituição Federal de 1988 e o Ministério da Educação e Cultura elabora vários documentos que destacam o cuidar e o educar como eixos estruturantes do trabalho nessas instituições, bem como a necessidade de formação dos profissionais para exercerem suas atividades laborativas nesses espaços, ressaltando as condições de trabalho, plano de carreira, salário e formação.

Já o terceiro período é marcado pela aprovação da Lei de Diretrizes e Bases (Lei no. 9.394/96) e pela entrada de recursos do Banco Mundial nas políticas de financiamento da educação infantil. A entrada do Banco Mundial nesse cenário traz à tona mais uma vez o antigo/atual modelo de educação de massa e de cunho assistencialista com propostas de ampliação da educação infantil com baixos investimentos nas estruturas físicas desses espaços, nos equipamentos, materiais didáticos e na formação dos profissionais.

Esse breve retrospecto do cenário histórico e político desta etapa da educação básica nos possibilita compreender que o perfil, a formação e a condição de trabalho docente dos profissionais que desempenham atividades pedagógicas nas creches e pré-escolas implicam e tem implicações nas políticas que norteiam e/ou nortearam essa etapa da educação.

Vieira e Souza (2010) salientam que no Brasil, nas últimas três décadas, a educação infantil esteve sob a chancela de duas áreas da administração pública nas instâncias federal, estadual e municipal - a Assistência Social, responsável pelas creches e pré-escolas e a Educação, pela pré-escola - compartilhando e disputando recursos, atribuições e mobilizando pessoal com diferentes status e qualificação profissional.

Pinto (2009) reitera que, ao longo da história, os profissionais que atuavam nas creches eram as educadoras leigas ou auxiliares, das quais eram exigidos conhecimentos básicos nas áreas de saúde, higiene e puericultura. A direção das creches era ocupada por médicos, assistentes sociais ou irmãs de caridade, prevalecendo assim o discurso da filantropia. Já nos jardins de infância, a tarefa de educar as crianças cabia às professoras, geralmente as normalistas. Nesse contexto, delinearam-se dois perfis de profissionais da educação infantil: as professoras da pré-escola, responsáveis pela educação das crianças e por sua preparação para o ingresso no ensino fundamental $\mathrm{e}$ as trabalhadoras das creches, chamadas de pajens, crecheiras, monitoras, etc., com salários e exigências menores para a formação profissional em relação às professoras, cuja função centrava-se em garantir um local limpo e seguro para as crianças passarem o dia.

De forma mais acentuada que nas demais etapas da educação básica, a Educação Infantil constitui-se como um locus por excelência de diversidade de formas de composição e organização do trabalho docente. Colaboram para isso os processos e origens históricas das instituições de Educação Infantil, o legado das políticas de assistência social e de educação, a composição nos municípios de instituições públicas e privadas (organizações comunitárias, filantrópicas etc.), a presença, em muitas redes, de uma 


\begin{abstract}
estrutura dual na composição do corpo docente - professores pertencentes à carreira do magistério e auxiliares de sala vinculados aos chamados quadros da carreira civil -, além da diversidade de terminologias e denominações dos grupos e profissionais que atuam na Educação Infantil. (VIEIRA; SILVA, 2009 apud VIEIRA; DUARTE, 2012, p. 206).
\end{abstract}

As questões aqui abordadas ratificam a desvalorização e o dualismo que envolvem os profissionais que trabalham com este segmento. Refletem ainda a estruturação histórica que compreendeu e ainda compreende a educação infantil como etapa da educação básica voltada apenas ao cuidar e ao âmbito das políticas educacionais centradas no assistencialismo, no voluntariado, o que tem certamente contribuído para as precárias condições de trabalho docente e para precarização do profissionalismo.

Campos (1999, p. 131), ao abordar as diferenças de origem, de identidade e de status entre as profissionais da educação, enfatiza que "quando consideramos os profissionais da educação, confirma-se por toda a parte a regra que estabelece que quanto menor a criança a se educar, menor o salário e o prestígio profissional de seu educador e menos exigente o padrão de sua formação prévia".

Para ilustrar tal constatação, recorremos mais uma vez a Campos et al. (2012) quando nos traz algumas conclusões de uma pesquisa sobre gestão infantil realizada em seis capitais brasileiras.

Muitos fatores contribuem para privar a creche de profissionais melhor qualificados e remunerados: 1) o recurso aos convênios, pois as entidades privadas tendem a empregar professores com formação mais precária, com jornadas mais longas e pior remuneração; 2) a contratação de educadores não docentes, em funções como auxiliares ou similares, reservando aos poucos professores as tarefas de "planejamentos de atividades" e/ou supervisão dos cuidados de higiene e alimentação; 3) sistemas pouco eficientes ou inexistentes de formação continuada e supervisão. (CAMPOS et al., 2012, p. 6).

Endossando tais premissas, Pascal et al. (1994) afirmam que é baixo o status do profissional que atende a educação infantil, pois trabalhar com crianças pequenas pressupõe menor esforço intelectual do que trabalhar com alunos maiores, e isso é perpetuado por vários fatores, a saber: baixos salários pagos a profissionais da educação infantil, ausência de perspectiva de progressão na carreira, a percepção de que essa não é uma atividade apropriada para homens e o nível mais baixo de formação para atender às crianças pequenas.

\section{A legislação e a condição de trabalho docente na educação infantil}

Como citado anteriormente, a compreensão da educação infantil enquanto espaço de educação coletiva é recente no Brasil e tem se colocado como um grande desafio a ser enfrentado tanto pelo Estado quanto pelos gestores municipais, que desde a Emenda Constitucional no 59/2009 que altera a Constituição no seu artigo 208 estabelece a obrigatoriedade escolar entre 4 e 17 anos, incluindo a educação ofertada em creches e préescolas entre os deveres do Estado. Essa alteração traz em seu bojo o desafio de se definir qual o profissional que trabalhará com essas crianças, bem como sua formação e suas condições de trabalho. Ficando sob a responsabilidade dos municípios a ampliação do direito à educação da infância.

Outro marco legal que alterou a concepção de atendimento à infância foi a Lei de Diretrizes e Bases da Educação Nacional (Lei no 9.394/96). Ela instituiu a inclusão da educação infantil, abrangendo o atendimento em creches e pré-escolas, como primeira etapa da educação básica. Dessa forma, a educação infantil tem sua compreensão (re)significada, à medida que o atendimento à infância passa a ser caracterizado como educacional, e deve ser pautado nas 
diretrizes e normas da educação. O prazo para que as creches e pré-escolas se integrassem aos sistemas de ensino foi estabelecido a partir de três anos da promulgação dessa Lei.

A Lei no 9.394/96 também alterou a compreensão do profissional que deveria trabalhar na educação infantil, como afirma Pinto (2009, p. 76):

Passou a conceituar a profissional de educação infantil como professora, definindo sua identidade e demandando sua participação na construção da proposta pedagógica da instituição em que trabalha (Art. 12 e Art.13). A formação básica das profissionais que atuam diretamente com as crianças de zero a seis anos $^{1}$ é definida pela LDB (Art. 62). Essa lei estabelece também os direitos das docentes (plano de carreira, condições adequadas de trabalho, tempo incorporado em sua carga horária de trabalho para formação e estudos) e os deveres (formação superior, admitida a formação mínima em nível médio, na modalidade normal).

Em 2001, o Plano Nacional de Educação no capítulo destinado à educação infantil apresentou metas para 0 atendimento das crianças de 0 a 6 anos, bem como adicionou "um novo paradigma ao conjunto normativo que orienta a remuneração dos docentes da educação básica nos desiguais estados e municípios brasileiros" (OLIVEIRA; VIEIRA, 2012, p. 49).

Em relação ao financiamento, a criação do Fundo de Manutenção e Desenvolvimento da Educação Básica e de Valorização dos Profissionais da Educação (FUNDEB), através da Emenda Constitucional no 53/2006, de 19 de dezembro de 2006 e sua consequente regulamentação, por meio da Lei no 11.494/2007, de 13 de novembro de 2007, trouxe para a educação infantil e para

\footnotetext{
${ }^{1}$ Em 2013, o art. 29 da LDB foi alterado através da Lei no 12.796 e a educação infantil passou a atender aos alunos de zero a 5 (cinco) anos de idade.
}

seus profissionais, uma importante conquista, a garantia de financiamento da educação de 0 a 5 anos, antes limitada apenas ao ensino fundamental. "Este fundo estabelece a perspectiva de per capita mínimos para cada etapa da educação básica e oferece a todas as etapas, da creche ao ensino médio, o beneficiamento de recursos federais, compromisso da União com este nível de escolarização que se estenderá até 2020". (SCHEIBE, 2010, p. 986).

Teixeira (2016, p. 192) discorre:

O Fundef criado pela Emenda Constitucional (EC) № $14 / 96$ e regulamentado pela Lei 9.424/96, [...] contribuiria indiscutivelmente para: 1) “o atendimento ao professor, valorizando o professor, incluindo a questão do salário"; 2) "valorizar o professor naquilo de que ele precisa também para sua dignidade" e melhorar a "condição de vida do professor"; 3) garantir uma "base mínima de formação de professor, de pagamento de professor"; e, 4) "melhorar o salário dos professores das áreas mais pobres" [...]. No Fundeb, Fundo substitutivo do Fundef, criado pela EC no 53, de 19 de dezembro de 2006, e regulamentado pela Lei $\mathrm{n}$ 응 11.494 , de 20 de junho de 2007 e pelo Decreto no 6.253 , de 13 de novembro de 2007, embora as entidades representativas do magistério público, a exemplo da Confederação Nacional dos Trabalhadores da Educação, tenham proposto e/ou solicitado a elevação do percentual a ser investido na remuneração docente para $80 \%$ dos recursos arrecadados no fundo, manteve-se o mesmo percentual do Fundef (60\%); apenas legitimou- 
se como elementos preponderantes para a valorização docente, o Plano de Carreira e a remuneração condigna, ao estipular prazo para a efetivação da lei do piso salarial profissional nacional.

A determinação de $60 \%$ de recursos para ser aplicado na remuneração docente trouxe melhorias salariais principalmente para as regiões Norte e Nordeste, onde a remuneração docente praticada era abaixo do que determinava o salário mínimo, todavia a inexistência de uma referência nacional para o início da carreira e a não injeção de novos recursos nas instâncias municipais e estaduais contribuíram para que o Fundo não atingisse o seu objetivo. Nessa direção, Oliveira e Vieira $(2013$, p. 11) salienta "o que podemos considerar um avanço, por outro lado, resultou em mudanças, no que se refere aos profissionais da educação básica, que pouco contribuem na direção de maior profissionalização".

No bojo dessas políticas que objetivam a valorização da educação infantil, destacam-se também as Diretrizes Curriculares Nacionais para a Educação Infantil e as Diretrizes Curriculares Nacionais Gerais para a Educação Básica. Essas Diretrizes tentam definir a função e os objetivos desta etapa na educação básica, a fim de orientar os processos de ensino e aprendizagem das crianças da educação infantil, bem como o trabalho pedagógico de seus professores.

O delineamento dessas políticas se constitui importante ação rumo à educação de qualidade para as crianças pequenas. Entretanto, existem ainda muitos enfrentamentos que envolvem a educação infantil resultantes das desigualdades e injustiças que se engendraram no seu processo histórico.

A ampliação desse direito tem resultado em maior atenção das políticas educacionais à Educação Infantil, fato recente na história do país. Concebida como assistência por longo período, a Educação Infantil se desenvolveu de forma periférica ao sistema escolar, como lugar de guarda, ou mesmo relegada à informalidade, à

filantropia, ao voluntariado e a arranjos domésticos. Essa experiência marcou profundamente esta etapa da educação básica, imprimindo determinadas identidades a esse trabalho que, ainda hoje, mais de 15 anos depois de essa etapa ser incluída no sistema educacional, ainda persistem. A Educação Infantil sofre de indefinição em relação a importantes aspectos de sua organização, de seus objetivos e de suas funções. O debate é complexo, envolvendo concepções de infância e de educação que permitem pensar esta etapa da educação básica para além do arremedo da forma escolar clássica, do currículo disciplinar e da educação como ensino e aprendizagem. (OLIVEIRA; VIEIRA, 2013, p. 9).

Outro marco legal importante para a melhoria do trabalho docente envolve a Lei no $11.738 / 2008$, que estabelece um piso salarial, profissional e nacional para uma jornada de trabalho de 40 horas semanais, e que deveria ser implantado progressivamente até 2010 , com a obrigatoriedade de reajustes anuais. Porém, sua efetivação é um desafio ainda, como afirma Scheibe (2010, p. 992):

Mesmo esta exigência mínima, que toma por base o pagamento para professores formados nos cursos de nível médio, é questionada por parte de alguns governantes estaduais, que entraram com uma Ação Direta de Inconstitucionalidade que fez com que o Supremo Tribunal Federal suspendesse temporariamente alguns dispositivos da lei. 
O piso salarial nacional para os profissionais do magistério público da educação básica é o valor mínimo que os docentes com formação em nível médio (antigo Curso Normal) e com carga horária semanal de 40 horas, em início de carreira devem receber. Para Teixeira (2016), isto implica em afirmar que os demais professores devam ter seu trabalho reconhecido/valorizado em termos salariais de acordo com seu tempo de serviço, sua formação/titulação acadêmica. E tais direitos e vantagens devem estar garantidas nos planos de carreira municipais da categoria, respaldados no piso salarial, profissional e nacional (PSPN), na Constituição Federal de 1988, na Lei de Diretrizes e Bases 9.394/96, na Lei do FUNDEB, etc.

A carreira e a remuneração dos profissionais da educação básica, após o FUNDEB, também foram objeto da nova regulamentação pelo Conselho Nacional de Educação (CNE), por meio do Parecer CNE/CEB 09/2009, que acompanha a Resolução CNE/CEB 02/2009. Tais documentos ratificam que o meio de acesso à carreira do magistério é o concurso público. Reafirmam ainda como elementos estruturantes dos planos de cargos e salários dos profissionais da educação a formação inicial e continuada e a composição da jornada de trabalho.

Ainda no tocante à legislação, a Câmara de Educação Básica do Conselho Nacional de Educação elaborou o Parecer no 17/2012, com o intuito de:

Orientar os sistemas de ensino e as instituições de Educação Infantil quanto aos aspectos fundamentais para a organização e funcionamento dessa etapa educacional, entre os quais se destacam: a carga horária, a jornada de atendimento, a organização e enturmação, o material pedagógico, a avaliação e a formação dos profissionais da Educação Infantil. [...]

Alguns sistemas de ensino defendem que na creche podem trabalhar profissionais não docentes coordenando os grupos infantis - auxiliares de desenvolvimento infantil, técnicos em

desenvolvimento infantil, recreacionistas,

monitores, pajens e outras denominações -, dado que a função desses profissionais não seria a de ensinar para crianças, mas a de socializa-las, garantir seu bem-estar. (BRASIL, 2012).

A dualidade que nasceu há séculos na nossa história recente, ainda se faz presente quando o assunto é o atendimento à educação infantil, reforçando assim o descaso e o descompromisso com a educação pública de qualidade para crianças pequenas, desconsiderando que neste segmento da educação básica, o cuidar, o brincar e o educar se constituem a tríade que o sustenta. Persiste ainda o discurso do cuidar, do assistencialismo, em detrimento do educar, que foi instituído pela Lei de Diretrizes e Bases desde 1996 e do precário profissionalismo para esse atendimento.

Os desafios elencados acarretam à necessidade de se repensar a formação para a docência na educação infantil. Vieira e Souza (2010, p. 127) apontam que:

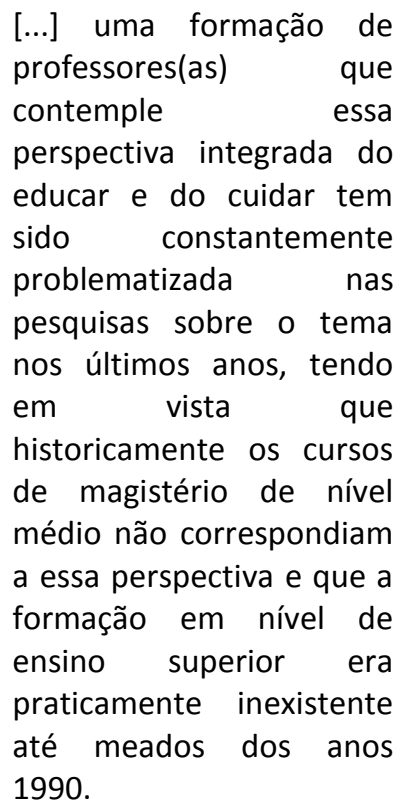

Nesse contexto, Campos (1994 apud PINTO 2009, p. 76) "adverte sobre a necessidade de uma visão integrada de educação infantil e também de um novo tipo de formação para as profissionais, que não hierarquize as atividades de educação e cuidado das crianças e não as 
segmente sob a responsabilidade de profissionais diferentes".

No tocante a essa discussão, a LDB no 9.394/96 que determinava a formação em nível superior para a docência na educação básica, teve sua redação alterada com a Lei no 12.014/2009 definindo que:

Art. 61: Consideram-se profissionais da educação escolar básica os que, nela estando em efetivo exercício e tendo sido formados em cursos reconhecidos, são:

I - professores habilitados em nível médio ou superior para a docência na educação infantil e nos ensinos fundamental e médio. (BRASIL, 2009, grifo nosso).

A formação mínima para atuar na docência da educação básica passa a ser a formação em nível médio. Assim, a formação passa a ter um viés mais instrumental e pragmático, com vistas a uma rápida expansão do fornecimento de professores, com redução de custos. Tal ação, consequentemente, aumenta o controle sobre a categoria e reforça a proletarização dos docentes na divisão social do trabalho, impactando na perda de status do professor. Sobre essa discussão, Oliveira e Vieira (2013, p. 11-12) nos convidam a refletir:

Dessa forma, a legislação brasileira passou a considerar que, para atuar na educação básica, incluindo aí a educação infantil como sua primeira etapa, pode-se obter formação em nível médio, sendo dispensável a formação superior. Essa medida reforça o que tem sido a prática de muitos gestores municipais: a de optarem por contratarem profissionais de formação de nível médio, com salários inferiores aos que são pleiteados pelos profissionais de nível superior. Essa prática assenta-se, em geral, na justificativa de que para cuidar de criança pequena não é necessária a

formação de nível superior, contribuindo para uma ideia de que a Educação Infantil pode ser exercida de forma amadora, por qualquer pessoa que se disponha a fazê-lo, sem a necessidade de uma preparação específica. Em última instância, não precisa ser profissional para atuar na educação da infância.

Tal exigência compromete o status do professor da educação básica, sua formação e, por conseguinte, a educação das crianças. Mais uma vez, o modelo de educação de massa e o barateamento dos serviços oferecidos vão de encontro do discurso da educação como direito social da criança. Nesse bojo, verifica-se a ênfase nos aspectos pragmáticos e instrumentais da formação, em cursos aligeirados, com ênfase a conhecimentos e saberes práticos em detrimento de uma formação política e consistente, que possibilite romper com princípios reprodutivistas de saberes e alienantes das condições de trabalho docente.

Condições alienantes que vão desde a falta de tempo para ficar em dia com a sua profissão, ocasionando a desqualificação até a sobrecarga de atividades profissionais que o impossibilita de interagir com seus pares e participar de cursos de formação continuada e/ou planejamentos em longo prazo, favorecendo a dependência de terceiros, e a desqualificação profissional, conforme ressalta Pinto (2009).

Um alerta acerca do desafio posto a respeito da formação dos profissionais da educação infantil é enunciado no Parecer no 17/2012 que ressalta "igualmente as instituições incumbidas da formação inicial e continuada dos professores de Educação Infantil" devem rever os currículos dos cursos de preparação para o magistério, a fim de atender aos requisitos postos pelo ordenamento legal e pela concepção técnica que tem se firmado a partir de pesquisas sobre o desenvolvimento e a aprendizagem de bebês e crianças menores de seis anos em espaços de educação coletiva (BRASIL, 2012). A esse respeito, Oliveira e Vieira (2013, p. 13) discute:

É necessário enfrentar as resistências e conceber a 
atuação docente distinta da tradicional grade de disciplinas, romper com a ideia de que para cuidar das crianças pequenas não é necessário ter formação específica, sendo algo natural da gênese feminina o cuidado e a atenção. Não é sem razão que a feminilização do magistério é muito mais presente na Educação Infantil e que, à medida que se avança na educação básica, aumenta a presença do sexo masculino entre os profissionais, ou seja, os homens estão mais presentes na segunda fase do Ensino Fundamental e no Ensino Médio como professores.

O desafio da formação docente se configura, assim, como um dos maiores enfrentamentos ao se pensar as condições de trabalho docente, pois pressupõe a revisão do status desse profissional, seu plano de carreira, sua remuneração, enfim sua profissionalização.

“Definir os tipos de
formação e especialização,
de carreira e de
remuneração para um
determinado grupo social
que vem crescendo e
consolidando-se, com a
entrada da Educação
Infantil como uma etapa
da educação básica e um
direito conquistado, é uma
tarefa presente da qual
não podemos fugir".
(OLIVEIRA; VIEIRA, 2013,
p.13-14).

Historicamente, a educação infantil forjou-se a partir do assistencialismo, do voluntariado, do descaso, do precário profissionalismo, o que inevitavelmente trouxe reflexos aos profissionais que atuam nesta etapa da educação básica, bem como as suas condições de trabalho docente. Pinto (2009, p. 82) afirma que "a construção atual no campo da educação da criança pequena no Brasil é marcada por tensões herdadas do passado, pelas promessas com as mudanças legais e pelas dificuldades no planejamento e na execução das políticas educacionais".

Tais obstáculos e tensões se colocam ainda mais desafiadores no atual momento histórico e político. Campos (2017) nos propõe uma reflexão a respeito do balanço crítico do cenário das políticas para educação infantil que vinham se delineando desde a Constituição de 1988, pois "ao invés de comentar questões pertinentes à continuidade de um processo relativamente coerente de construção de um arcabouço legal e institucional para crianças pequenas, fomos jogadas a contragosto para uma posição muito diferente". (CAMPOS, 2017, p.1)

Esse cenário turbulento, instável e ameaçador se materializa em ações até então impensáveis, como o teto de 20 anos para gastos sociais, como o descumprimento das metas, diretrizes e estratégias do Plano Nacional de Educação (PNE - 2014/2024) e como a nova política para formação de professores.

Essa nova política de formação de professores, anunciada em 18 de outubro de 2017 e lançada em 28 de fevereiro de 2018, sob a égide da Residência Pedagógica, materializa-se como um modelo de estágio conservador, ao se organizar a partir do discurso da hora da prática (item 1 e 2 - Edital Capes no 06/2018, p.1).

A residência pedagógica
terá o total de 440 horas
de atividades distribuídas
da seguinte forma: 60
horas destinadas à
ambientação na escola;
320 de imersão, sendo 100
de regência, que incluirá o
planejamento e execução
de pelo menos uma
intervenção pedagógica; e
60 horas destinadas à
elaboração de relatório
final, avaliação e
socialização de atividades.

Esse formato reduz o fazer pedagógico a momentos pontuais desprovidos de reflexão e destoam da compreensão do estágio enquanto pesquisa, à medida que retoma a formação assentada nos princípios do pragmatismo - do como fazer. Além dessas questões, esse projeto traz em seu bojo a exigência do diálogo com a Base Nacional Curricular Comum (BNCC). Tal vinculação obriga as instituições formadoras a organizarem seus currículos alinhados à BNCC, 
corroborando assim para uma concepção de currículo, conhecimento, docência e escola reducionista, fragmentada e empobrecida. A Residência Pedagógica condicionada à BNCC pressupõe estar também condicionada às exigências e expectativas dos gestores das escolas da educação básica, restando à universidade condicionar seu trabalho, a fim de atender tais demandas, o que compromete a sua autonomia e os princípios epistemológicos de formação conforme destaca a manifestação das entidades educacionais sobre política de formação de professores apresentada pela ANPED em audiência no Conselho Nacional de Educação em 2018.

\section{Os modos de ser e estar professor na educação infantil: os sentidos que os professores atribuem a sua formação continuada}

Para Veiga (1998, p.15), a "formação assume uma posição de "inacabamento", vinculada à história de vida dos sujeitos em permanente processo de formação, que proporciona a preparação profissional". Nessa perspectiva, definir a formação docente é compreendê-la como uma construção inacabada, dinâmica, dialética e flexível. Reiterando essa ideia, Freire (2011) destaca que a formação é um fazer permanente que se refaz continuamente na ação. E Alarcão (1998) a define como o processo dinâmico por meio do qual, ao longo do tempo, um profissional vai adequando sua formação às exigências de sua atividade profissional.

Ainda, segundo Veiga (1998), o processo de formação é multifacetado, plural, tem início e nunca tem fim. Seu início na educação infantil é demarcado pelos documentos oficiais como formação inicial exigida, o ensino superior, aceita a modalidade de nível médio, na modalidade normal. Já o seu fim, é continuamente perseguido através da formação continuada, traduzida numa perspectiva de formação realizada ao longo da vida profissional do professor, conforme destaca a Lei n. 9.394, de 20 de dezembro de 1996, Lei de Diretrizes e Bases da educação (LDB):

Art. 61. A formação de profissionais da educação, de modo a atender aos objetivos dos diferentes níveis e modalidades de ensino e as características de cada fase do desenvolvimento do educando, terá como fundamentos:

I - a associação entre teorias e práticas, inclusive mediante a capacitação em serviço;

II - aproveitamento da formação e experiências anteriores em instituições de ensino e outras atividades.

Art. 62. A formação de docentes para atuar na educação básica far-se-á em nível superior, em curso de licenciatura, de graduação plena, em universidades e institutos superiores de educação, admitida, como formação mínima para o exercício do magistério na educação infantil e nas quatro primeiras séries do ensino fundamental, a oferecida em nível médio, na modalidade Normal. (BRASIL, 1996).

Como processo contínuo, dialético, eminentemente humano, as trajetórias formativas precisam ser consideradas enquanto práticas sociais, desenvolvidas em contextos de coletividade.

Nesse contexto de inacabamento e condicionada por inúmeros fatores que se interrelacionam, a formação docente está intrinsecamente associada à relação teoria e prática e à reflexão sobre a prática educativa. Estas vêm carregadas de sentido e complexidade no que se referem à formação de professores, pois transcendem, rompem com o ensino burocratizado, linear, pragmático e imediatista.

Essa espiral contínua de ação-reflexãoação possibilita ao professor olhar criticamente sua ação pedagógica, a fim de perceber suas falhas e acertos e avançar de um ativismo prático à práxis, e promover ressignificações concretas em seu modo de pensar e agir.

Partindo dessas premissas, o que diferenciaria a formação dos educadores de crianças pequenas dos demais educadores? Essa caracterização perpassa pela compreensão das especificidades da faixa etária das crianças, pela vulnerabilidade da infância, por sua forma global de compreender o mundo, e consequentemente, 
de produzir conhecimentos. Gomes (2009) reitera que o professor da educação infantil deve:

Ser um profissional capaz de promover múltiplas interações envolve o acolhimento e a ideia de pertença grupal, a dimensão afetiva, o respeito às necessidades $\mathrm{e}$ interesses das crianças, aos seus padrões culturais, captando-os para os propósitos do trabalho desenvolvido, a ampliação permanente de seu universo sociocultural, novo dimensionamento para o educar, para o ensinar e o aprender, a permanente reflexão sobre os propósitos que guiam suas práticas, as concepções que dão suporte às ações e, não menos importante, 0 estímulo à construção de um propósito de identidade profissional que possa conduzi-lo a olhar o próprio percurso formativo em uma perspectiva de desenvolvimento profissional.

(GOMES, 2009, p.54).

Quando provocados a falar sobre os processos formativos da rede municipal de ensino de Guanambi - BA no tocante à educação infantil, todos os sujeitos envolvidos nesta pesquisa sinalizam sua preocupação em relação à diminuição de tempos e espaços coletivos destinados à formação, conforme se pode verificar nas CIPs transcritas a seguir:

Hoje limitou essa
participação, o
oferecimento de cursos
para os professores e
quando se oferece é on
line ou nos planejamentos
no CETEP, porém agora
limitou-se mais. Agora
temos a coordenação na
creche, o que melhorou
também, mas em termo
de formação continuada
para a creche não está

tendo mais. (Sandra, CIP 2017).

A gente quase não tem formação continuada no momento. Igual agora mesmo, como recebemos os livros, a gente tem apenas um dia de formação da Positivo, que também é assim mais apresentação do material. Esse último encontro foi melhor um pouquinho, mas os outros era só mesmo para apresentar o material, eu sinto falta, porque quando a gente está fazendo os cursos, a gente tem mais interesse em estar lendo, estar atualizando e assim a troca de experiência é muito boa. Eu sinto falta. (Tereza, CIP 2017).

A formação era boa, mas antes, bem antes, quando trabalhava todo mundo junto, quando tinha aqueles planejamentos. Eu não sei porque foi no início, porque a gente estava começando, todo mundo empolgado. Eu comecei a aprender naquele tempo, depois eu tomei um curso Um salto para o futuro, o primeiro que teve aqui, ô curso bom, meu Deus! Aquele curso foi bom demais, era à noite, na época pareceu um "pipoco" assim na minha vida, eu não esqueço até hoje. Às vezes passa nos cursos que tem hoje, as coisas que passou lá, passa tudo agora, e eu falo eu já sabia disso aí.

Hoje ainda tem no CETEP, mas eu acho frio, não sei se são as meninas, as colegas, as leituras ou o povo está muito cansado, não é mais como antes, que parecia que a gente ia para uma festa. Parece que está acabando o 
encanto de tudo, o professor reclama de tudo, eu mesma reclamo, tenho o direito de reclamar, pois eu estou cansada e é de muito tempo. Eu não reclamo muito, porque às vezes o povo fala assim: "por que você não se aposentou?" (Maria, CIP 2017).

Eu peguei algumas coisas. Teve alguns cursos lá no CETEP. Este ano não tem, este ano está mais assim! Como os coordenadores estão na escola, quase não está tendo cursos de formação, não!

Mas de educação infantil, eu não participava de tantos cursos de formação, como no primeiro ano, não! Mas eu fui fazendo alguns pela internet. Eu fiz até uma especialização em uma faculdade particular para eu aprender mais. É à distância, mas meu intuito é porque eu tinha aluno especial e eu não entendia ele. Meu intuito era eu estudar, entendeu? Se eu ficar sem fazer nada, eu acabava não estudando, não aprendendo sobre ele, então eu decidi fazer a especialização em Psicopedagogia lá, aí eu vou assistindo os vídeos, eu vou lendo, mesmo que eles não dão esse apoio que a gente sabe que não é, né? Eu fiz uma de Práticas Docentes Interdisciplinares em Caetité, que é outra coisa, lá é outra coisa. É totalmente diferente, na de lá eu aprendi mais também, na época me fez interrogar muitas coisas, me fez no dia a dia da sala de aula, ver algo que eu não precisava mudar. Aí eu fiz outros cursos de capacitação, eu acabo fazendo cursos de capacitação pra mim não ficar estagnada. (Isabel, CIP 2017).

Pode-se depreender ainda dessas falas a ausência nos últimos anos, em especial no ano de 2017, da participação de estudos coletivos, o que pode vir a causar o isolamento do professor, a desarticulação do coletivo da categoria e consequentemente diminuir a perspectiva do fortalecimento do trabalho docente.

A garantia de $1 / 3$ da carga horária destinada aos processos formativos se configura como um avanço para o professor, conforme relatos anteriores dos sujeitos pesquisados, entretanto faz-se necessário um planejamento por parte da equipe gestora, a fim de garantir espaço coletivo de estudo e trocas entre os pares. Além disso, os sujeitos apontam a necessidade de a Secretaria Municipal de Educação do município de Guanambi definir uma política de formação continuada para os professores da rede.

Isabel salienta a necessidade de buscar aperfeiçoamento profissional para responder às necessidades do trabalho docente, no entanto esta busca se dá por conta própria, por sua própria iniciativa, como se fosse responsabilidade de cada profissional exercer a auto vigilância sobre seu processo formativo.

Nesse contexto, Ball (2002, p. 8) destaca que "o trabalho do gestor envolve o instalar da atitude e da cultura segundo a qual o trabalhador se sente, ele próprio, responsável e ao mesmo tempo comprometido ou pessoalmente empenhado na organização".

O cenário delineado até aqui se justifica à medida que se compreende as influências dos organismos internacionais, como Organização dos Estados Americanos (OEA), Banco Interamericano de Desenvolvimento (BID), Banco Mundial (BM), Comunidade Europeia (CE), Organização para Cooperação Desenvolvimento Econômico (OCDE), Programa das Nações Unidas para o Desenvolvimento (PNUD), Programa das Reformas Educacionais da América Latina e Caribe (PREAL), dentre outras, em relação às reformas neoliberais que se desencadearam a partir da década de 1990 no Brasil.

Essas organizações passaram a exercer forte influência na definição das diretrizes educacionais, nos países em 


\begin{abstract}
desenvolvimento, como no caso do Brasil, apontando condições essenciais para melhores resultados na educação, que envolvem maior flexibilidade das leis e normas de contratação docente, incentivos salariais seletivos, recompensas não monetárias, ampliação do tempo exigido para aposentadoria, maior ênfase na formação por habilidades que nos conteúdos informativos e a premiação das escolas e professores pelos bons resultados nas avaliações externas. (BRITO et al., 2017, p.168).
\end{abstract}

Ball (2010) destaca ainda que a preocupação com as questões educacionais cede lugar às demandas do mercado, pois a educação passa a ser considerada um bem de consumo e os docentes transformados em mercadorias, obrigados a assumir a mercantilização de sua força de trabalho e de seu conhecimento.

A presença de momentos pontuais fomentados em parceria com a editora Positivo ${ }^{2}$ traz à baila outro aspecto que envolve esse cenário, como o sistema apostilado de ensino e que tem ganhado cada vez mais espaço nos processos formativos do Brasil. Tal adoção reflete o avanço do setor privado sobre a política educacional local.

A "cesta" que compõe os contratos firmados entre as prefeituras municipais e a iniciativa privada é integrada por atividades tradicionalmente

desenvolvidas pelas equipes pedagógicas dos órgãos da administração pública e das escolas: formação continuada de educadores, efetivo acompanhamento das

\footnotetext{
${ }^{2}$ Nos anos de 2016 e 2017, a prefeitura municipal de Guanambi efetivou uma parceria com a Editora Positivo. Esta parceria preconiza a aquisição de livros didáticos para as turmas da préescola da rede municipal. Assim sendo, a editora realiza semestralmente um momento formativo de apresentação da coleção para os professores que trabalharão com o material. Tratase de uma formação exclusiva para utilização dos livros.
}

atividades docentes; investimento na produção e distribuição de materiais didáticos aos alunos; processos de avaliação externa e interna, entre as principais encontradas. Por essa razão, para além dos problemas pedagógicos derivados da adoção de material instrucional, em alguns casos desde a pré-escola, - que é importante destacar é o fato de que as empresas privadas passam, a vender os chamados "sistemas de ensino", a interferir na gestão do próprio sistema escolar público local. (ADRIÃO et al., 2009, p. 806).

Tereza Adrião, em sua fala, destaca que os encontros fomentados pela editora se resumem à apresentação do material, a formação assim é compreendida como um momento pontual e o professor um mero reprodutor do material didático.

Outra preocupação relacionada à introdução de formas de parcerias públicoprivadas é reforçada por Hypolito (2012) quando ele afirma que essas parcerias tanto no âmbito da gestão quanto no ensino reforçam o controle do estado sobre os currículos, por meio de exames e avaliação, reduzindo a autonomia e o controle do professor sobre seu trabalho pedagógico. Tal controle acarreta um alinhamento do currículo com os exames e testes, com empobrecimento curricular e um possível empobrecimento curricular também dos cursos de formação docente.

O acompanhamento pedagógico também é evidenciado na fala dos professores, a presença dos coordenadores na escola é vista como uma conquista, principalmente se esse trabalho é pautado por processos sistemáticos de reflexão compartilhada sobre a prática em situações de interação entre professores e coordenadores pedagógicos. Todavia, o preço pago resultou na dissolução dos momentos formativos coletivos e dos momentos de estudo, conforme destaca Sandra.

Para Maria, os processos formativos foram perdendo o encanto com o decorrer do 
tempo, e uma possível justificativa foi o cansaço do professor. Cansaço decorrente de uma jornada de trabalho extensa, de sobrecarga de atividades e maior envolvimento físico e emocional com o trabalho.

Forjar um processo formativo que atenda a todas as questões pontuadas neste texto é um desafio, pois os espaços e tempos formativos atualmente se caracterizam como momentos formativos aligeirados, pontuais, que evidenciam a desarticulação entre a teoria e a prática e pouco colaboram para a adoção de uma atitude investigativa ou reflexiva. É comum ainda a utilização por alguns gestores públicos, de expressões como "treinamento", "cursos de reciclagem", "capacitação", em que há prevalência da teoria sobre a prática ou mais comumente o contrário, sugestões práticas de aulas modelares, evidenciando a influência dos organismos internacionais na definição desses processos.

\section{CONCLUSÕES}

A partir das discussões elencadas, ao longo deste artigo, conclui-se que o perfil, a formação e a condição de trabalho docente dos profissionais que desempenham atividades pedagógicas nas creches e pré-escolas implicam e tem implicações nas políticas que norteiam e/ou nortearam essa etapa da educação. Desse modo, compreender os aspectos históricos e políticos da educação infantil possibilita compreender como eles se configuram como marcos na construção de políticas públicas para esse segmento da educação básica.

As questões aqui abordadas ratificam a desvalorização e o dualismo que envolvem os profissionais que trabalham na educação infantil. Refletem ainda a estruturação histórica que compreendeu e ainda compreende a educação infantil como etapa da educação básica voltada apenas ao cuidar e ao âmbito das políticas educacionais centradas no assistencialismo, no voluntariado, o que tem certamente contribuído para as precárias condições de trabalho docente e para precarização do profissionalismo. A dualidade reforça o descaso e o descompromisso com a educação pública de qualidade para as crianças pequenas, desconsiderando que neste segmento da educação básica, o cuidar, o brincar e o educar se constituem a tríade que o sustenta.

O delineamento das políticas que contemplam a educação infantil se constitui importante ação rumo à educação de qualidade para as crianças pequenas. Entretanto, existem ainda muitos enfrentamentos que envolvem a educação infantil resultantes das desigualdades e injustiças que se engendraram no seu processo histórico. Dentre eles, o da formação docente se configura como um dos maiores ao se pensar as condições de trabalho docente, pois pressupõe a revisão do status desse profissional, seu plano de carreira, sua remuneração, enfim sua profissionalização.

Quando provocados a falar sobre os processos formativos da rede municipal de ensino de Guanambi - BA no tocante à educação infantil, todos os sujeitos envolvidos nesta pesquisa sinalizaram sua preocupação em relação à diminuição de tempos e espaços coletivos destinados à formação. Ressaltaram também que a garantia de $1 / 3$ da carga horária destinada aos processos formativos se configura como um avanço para o professor, entretanto faz-se necessário um planejamento por parte da equipe gestora, a fim de garantir espaço coletivo de estudo e de trocas entre os pares. Além disso, os sujeitos apontaram a necessidade de a Secretaria Municipal de Educação do município de Guanambi definir uma política de formação continuada para os professores da rede.

A presença dos coordenadores na escola é vista pelos professores como uma conquista, principalmente se esse trabalho é pautado por processos sistemáticos de reflexão compartilhada sobre a prática em situações de interação entre professores e coordenadores pedagógicos. Todavia, o preço pago resultou na dissolução dos momentos formativos coletivos e dos momentos de estudo.

A presença de momentos pontuais fomentados em parceria com a editora Positivo evidencia um cenário marcado pela presença do sistema apostilado de ensino, que tem ganhado cada vez mais espaço nos processos formativos do Brasil. Tal adoção reflete o avanço do setor privado sobre a política educacional local.

Os sentidos atribuídos pelos professores deste estudo à formação continuada revelam desafios e tensões que demandam enfrentamentos e resistência por parte da categoria, principalmente no atual momento histórico e político, marcado por um cenário turbulento, instável e ameaçador que se materializa em ações até então impensáveis e que afetam diretamente os setores sociais como a educação. 


\section{REFERÊNCIAS}

ADRIÃO, T. et al. Uma modalidade peculiar de privatização da educação pública: a aquisição de "sistemas de ensino" por municípios paulistas. Educação e Sociedade, Campinas, v. 30, n. 108, p. 799-818, 2009. https://doi.org/10.1590/S010173302009000300009

ALARCÃO, I. Formação continuada como instrumento de profissionalização docente. In: VEIGA, I. P. A. (Org.). Caminhos da profissionalização do magistério. Campinas: Papirus, 1998. p. 99-122.

ALVES-MAZZOTTI, A. J.; GEWANDSZNAJDER, F. O método nas ciências naturais e sociais: pesquisa quantitativa e qualitativa. 2.ed. São Paulo: Pioneira Thomson Learning, 2004.

BALL, S. Performatividade e fabricações na economia educacional: rumo a uma sociedade performativa. Educação e Realidade, Faculdade de Educação da Universidade Federal do Rio Grande do Sul, v. 2, n. 32, p. 37-55, 2010.

BALL, S. Reformar escolas/reformar professores e os terrores da performatividade. Revista Portuguesa de Educação, Braga-Portugal, Universidade do Minho, v. 15, n. 2, p. 3- 23, 2002.

BOGDAN, R.; BIKLEN, S. K. Investigação qualitativa em educação: uma introdução à teoria e aos métodos. Porto, Portugal: Porto Editora, 1994.

BRASIL. Edital CAPES 06/2018 que dispõe sobre a residência pedagógica. Brasília: MEC, 2018. Disponível em: capes.gov.br/images/stories/download/editais/0 1032018-Edital-6-2018-\%20esidenciapedagogica.pdf. Acesso em: 01 out. 2019.

BRASIL. Lei no 11.738, de 16 de julho de 2008. Regulamenta a alínea "e" do inciso III do caput do art. 60 do Ato das Disposições Constitucionais Transitórias, para instituir o piso salarial profissional nacional para os profissionais do magistério público da educação básica. Brasília: Presidência da República, 2008. Disponível em: http://www.planalto.gov.br/ccivil_03/_ato20072010/2008/lei/l11738.htm. Acesso em: 11 set. 2017.
BRASIL. Lei n. 12.014, de 6 de agosto de 2009. Altera o art. 61 da Lei n. 9.394, de 20 de dezembro de 1996, com a finalidade de discriminar as categorias de trabalhadores que se devem considerar profissionais da educação. Diário Oficial da União, Brasília-DF, 07 ago. 2009. Brasília: Presidência da República, 2009. Disponível em:

http://www.planalto.gov.br/ccivil_03/_ato20072010/2009/lei/l12014.htm. Acesso em: 12 set. 2019.

BRASIL. Ministério da Educação. Lei de Diretrizes e Bases da Educação Nacional: Lei no 9.394 de 20 de dezembro de 1996. Brasília: MEC, 1996.

BRASIL. Parecer n. 17/2012. Orientações sobre a organização e o funcionamento da educação infantil, inclusive sobre a formação docente, em consonância com as diretrizes curriculares nacionais para a educação infantil. Brasília: Presidência da República Disponível em: http://portal.mec.gov.br/index.php?option=com _docman\&view=download\&alias=14597pceb017-12-2\&category_slug=novembro-2013pdf\&Itemid=30192. Acesso em: 03 out. 2019.

BRITO, R. S.; PRADO, J. R.; NUNES, C. P. As condições de trabalho docente e o pós-estado de bem-estar social. Revista Tempos e Espaços em Educação, Sergipe, v. 10, n. 23, p. 165-174, 2017. https://doi.org/10.20952/revtee.v10i23.6676

CAMPOS, M. M. A formação de professores para crianças de 0 a 10 anos: modelos em debate. Educação e Sociedade, Campinas, v. 20, n. 68, p. 126-142, 1999. https://doi.org/10.1590/S010173301999000300007

CAMPOS, M. M. Balanço analítico da educação infantil: direitos em risco e consensos possíveis. São Luís: ANPED, 2017. Disponível em: http://www.38reuniao.anped.org.br/.../trabalho encom_38anped_2017_gt07_textomariamaltaca m. Acesso em: 06 out. 2019.

CAMPOS, M. M. et al. A gestão da educação infantil no Brasil. Estudos e pesquisas educacionais, São Paulo, n. 3, p. 29-102, 2012.

FREIRE, P. Pedagogia da autonomia: saberes necessários à prática educativa. 43.ed. São Paulo: Paz e Terra, 2011. 
GOMES, M. O. Formação de professores na educação infantil. São Paulo: Cortez, 2009.

HYPOLITO, Á. M. Trabalho docente na educação básica no Brasil: as condições de trabalho. In: OLIVEIRA, D. A.; VIEIRA, L. M. F. (Org.). Trabalho na educação básica: a condição em sete estados brasileiros. Belo Horizonte: Fino Traço, 2012. p. 211-229.

MANIFESTAÇÃO das entidades educacionais sobre a política de formação de professores anunciada pelo MEC. [s. l.]: ABdC: ABRAPEC: ANFOPE: ANPA: ANPEd: CEDES: FINEDUCA: FORUMDIR, 2017. Disponível em: http://www.anped.org.br/sites/default/files/nota daentidades_-_31.10.17comlogo.pdf. Acesso em: 05 out. 2019.

NUNES, C. P. Ciências da educação e prática pedagógica: sentidos atribuídos por estudantes de Pedagogia. Ijuí: Unijuí, 2011.

OLIVEIRA, D. A.; VIEIRA, L. M. F. Condições de trabalho docente: uma análise a partir de dados de sete estados brasileiros. In: OLIVEIRA, D. A. O.; VIEIRA, L. M. F. (Org.). Trabalho na educação básica: a condição em sete estados brasileiros. Belo Horizonte: Fino Traço Editora, 2012. p. 153190.

OLIVEIRA, D. A.; VIEIRA, L. M. F. (Org.). Trabalho docente: desafios e cotidiano da educação básica. Campinas: Editora Mercado de Letras, 2013. p. 153-190.

PASCAL, C.; BERTRAN, A.; HEASLIP, P. Mudanças no contexto da formação do educador infantil na Europa. In: ROSEMBERG, F.; CAMPOS, M. M. (Org.). Creches e pré-escolas no hemisfério Norte. São Paulo: Cortez, 1994. p. 299-322.

PINTO, M. F. O trabalho docente na educação infantil pública em Belo Horizonte. 2009. $194 \mathrm{f}$. Dissertação (Mestrado em Educação) - Faculdade de Educação, UFMG, Belo Horizonte, 2009.

ROSEMBERG, F. Políticas de educação infantil e avaliação. Cadernos de Pesquisa, São Paulo, v. 43, n. 148, p. 44-75, 2003.

https://doi.org/10.1590/S0100-

15742013000100004
SCHEIBE, L. Valorização e formação dos professores para a educação básica: questões desafiadoras para um novo plano nacional de educação. Educação Sociedade, Campinas, v. 31, n. 112, p. 981-1000, 2010.

https://doi.org/10.1590/S0101$\underline{73302010000300017}$

TEIXEIRA, E. C. N. S. Impactos da lei do piso salarial nacional no município de Pindaí - BA e suas implicações na valorização docente: sentidos dos/as professores/as. 2016. 241 f. Dissertação (Mestrado em Educação) Universidade Estadual do Sudoeste da Bahia, Vitória da Conquista, 2016.

VEIGA, I. P. A. Profissão docente: novos sentidos, novas perspectivas. Campinas: Papirus, 1998.

VIEIRA, L. M. F.; SOUZA, G. Trabalho e emprego na educação infantil no Brasil: segmentações e desigualdades. Educar em Revista, Curitiba, Brasil, n. 1, p. 119-139, 2010. https://doi.org/10.1590/S0104$\underline{40602010000400006}$

VIEIRA, L. M. F.; DUARTE, A. Professores da educação infantil no Brasil: Desigualdades no trabalho docente e no status social. In: OLIVEIRA, D. A.; FELDFEBER, M.; ESCOBAR, R. G. Educación y trabajo docente em el nuevo escenario latinoamericano: entre la mercantilización del conocimiento. Peru: Fondo Editorial, 2012. p. 195-2016. 